\title{
PENGARUH GAYA KEPEMIMPINAN TRANSFORMASIONAL, TRANSAKSIONAL, KEPUASAN KERJA TERHADAP $O C B$ KARYAWAN PT.KONSTRINDO PUTERA PERKASA
}

\author{
BATARA ARIANSYAH INDRA \\ IDRIS AZIS \\ YOBERT KORNELIUS \\ Jurusan Manajemen, Fakultas Ekonomi, Universitas Tadulako \\ Email: batara1708@gmail.com
}

\begin{abstract}
This study aims to find out Transformational Leadership Style, Transactional Leadership Style and Job Satisfaction have influence, either simultaneously or partially, to Organizational Citizenship Behavior (OCB) Employee PT.Konstrindo Putera Perkasa. The sample in this study using all the population with the method used is saturated or census sampling. Data collection was done by using questionnaires, interviews, and through observation (observation). This study uses Multiple Linear Regression Analysis Method with the help of computer program SPSS For Windows Release 17.0.The result of hypothesis analysis and testing can be concluded that: (1) based on results obtained by Sig.F $0.000<0,05$, which can be interpreted that the variables of transformational leadership style, transactional leadership style and job satisfaction simultaneously affect the Organizational Citizenship Behavior (OCB) variable. (2) based on the regression test results, the variables of transformational leadership style have significance level $t$ sig. $(0,000)<\alpha(0,05)$, transactional leadership style variable has significance level t sig. $(0.019)<\alpha(0,05)$ and job satisfaction variable have significance level $t$ sig. $(0,05)<\alpha(0,05)$, so that variable of transformational leadership style, transactional leadership style and satisfaction of work partially influence to organizational citizenship Behavior (OCB) variable (3) based on result of regression test obtained variable which influenced most dominant is transformational leadership style has the highest Beta value is 0.708
\end{abstract}

Keywords: Transformational, Transactional, Job Satisfaction, OCB.

ABSTRAK

Penelitian ini bertujuan untuk mengetahui Gaya Kepemimpinan Transformasional ,Gaya Kepemimpinan Transaksional dan Kepuasan Kerja mempunyai pengaruh, baik secara simultan maupun secara parsial, terhadap Organizational Citizenship Behavior (OCB) Karyawan PT.Konstrindo Putera Perkasa, Sampel dalam penelitian ini menggunakan seluruh populasi dengan metode yang digunakan yaitu sampling jenuh atau sensus. Pengumpulan data dilakukan dengan menggunakan kuesioner, wawancara, dan melalui pengamatan (observasi). Penelitian ini menggunakan Metode Analisis Regresi Linear Berganda dengan bantuan program komputer SPSS For Windows Release 17.0. Hasil analisis Uji F disimpulkan bahwa variabel gaya kepemimpinan transformasional, gaya kepemimpinan transaksional dan kepuasan kerja secara serempak berpengaruh terhadap variabel Organizational Citizenship Behavior (OCB) sedangkan Uji T disimpulkan variabel gaya kepemimpinan transformasional, gaya kepemimpinan transaksional dan kepuasan kerja secara parsial berpengaruh terhadapvariabel Organizational Citizenship Behavior (OCB)

Kata Kunci: Transformasional, Transaksional, Kepuasan Kerja, OCB.

\section{PENDAHULUAN}

Organizational Citizenship Behavior (OCB) atau perilaku organisasi kewargaan merupakan perilaku yang dapat meningkatkan produktivitas tenaga kerja. Tenaga kerja selaku motor organisasi diharapkan untuk memiliki skill dan perilaku yang baik serta harus bisa memberikan kinerja terbaiknya untuk perusahaan, dalam mencapai tujuan perusahaan.

Organizational Citizenship Behavior $(O C B)$ tidak serta merta dapat terwujud sehingga Robbins mengemukakan teori bahwa Organizational Citizenship Behavior (OCB) dapat terwujud melalui 
perilaku gaya kepemimpinan dalam perusahaan, tanggung jawab dari seorang pimpinan organisasi adalah mengarahkan bawahan ke arah pencapaian tujuan organisasi dengan jalan mengartikulasikan misi,visi, strategi, dan sasaran-sasaran. Bass membagi kepemimpinan menjadi dua gaya kepemimpinan yaitu gaya kepemimpinan transformasional dan gaya kepemimpinan transaksional, dimana gaya kepemimpinan tersebut menjelaskan adanya sinergitas dan transaksi antara pimpinan dan bawahan dalam menjalankan organisasi.

Gaya kepemimpinan transformasional adalah pemimpin yang menginspirasi para pengikutnya untuk mengenyampingkan kepentingan pribadi mereka demi kebaikan organisasi dan mereka mampu memiliki pengaruh yang luar biasa pada diri para pengikutnya. dan gaya kepemimpinan transaksional yaitu, pemimpin memberikan imbalan atas usaha-usaha bawahan yang telah dilakukannya bagi organisasi (Robbins dalam Supit, 2016).

Selain gaya kepemimpinan Robbins juga menjelaskan Organizational Citizenship Behavior (OCB) dapat muncul dari kepuasan kerja karyawan dalam perusahaan. Ketika karyawan merasa puas atas pekerjaan nya, maka karyawan tersebut akan lebih maksimal dalam menyelesaikan tugasnya serta akan bertindak ekstra diluar standar tugas yang diberikan.

Kepuasan kerja adalah suatu perasan positif tentang pekerjaan seseorang yang merupakan hasil dari sebuah evaluasi karakteristiknya. Kepuasan kerja juga merupakan penentu utama dalam memicu timbulnya Organizational Citizenship Behavior (OCB) (Robbins dalam supit 2016)).

Perusahaan PT. Konstrindo Putra Perkasa bergerak pada bidang Jasa Konstruksi, Pertambangan, pembersihan lahan (kelapa sawit, percetakan sawah dan lainnya) dan penyewaan alat berat penunjang dalam pertambangan. Telah banyak Proyek yang telah dikerjakan oleh perusahaan ini, dan banyak menuai kritikan positif dari masyarakat sekitar tempat proyek seperti di: Pembukaan Lahan Perkebunan, Pertambangan, Pekerjaan Jalan, Pekerjaan Irigasi, Pelabuhan dan Dermaga.. Kantor pusat perusahaan ini terletak dijalan Jl. Soekarno Hatta Ruko Perum Pesona Nokilalaki No.5.

Terdapat masalah yang terjadi menurut beberapa karyawan, mereka berpendapat bahwa masih banyak kekurangan yang dimiliki pimpinan dan karyawan pada PT.Konstrindo Putera Perkasa ini, seperti kurangnya rasa saling membantu antara karyawan dan waktu pimpinan untuk membina sangat terbatas dikarenakan pimpinan di perusahaan ini sering keluar kota, banyak karyawan yang masih ragu-ragu dengan hasil kinerjanya, dan banyak karyawan yang memberikan pernyataan bahwa mereka kurang percaya diri dalam menyelesaikan tugas yang diberikan pimpinan.

Berdasarkan uraian diatas yang melatar belakangi penelitian ini, maka dapat dirumuskan beberapa masalah yaitu: Apakah gaya kepemimpinan transformasional, gaya kepemimpinan transaksional, dan kepuasan kerja karyawan berpengaruh Simultan/Serempak dan signifikan terhadap Organizational Citizenship Behavior (OCB) pada karyawan PT. Kronstrindo Putera Perkasa, Apakah gaya kepemimpinan transformasional berpengaruh parsial dan signifikan terhadap Organizational Citizenship Behavior (OCB) pada karyawan PT. Kronstrindo Putera Perkasa, Apakah gaya kepemimpinan transaksional berpengaruh parsial dan signifikan terhadap Organizational Citizenship Behavior $(O C B)$ pada karyawan PT. Kronstrindo Putera Perkasa, Apakah kepuasan kerja karyawan pemimpin berpengaruh parsial dan signifikan terhadap Organizational Citizenship Behavior (OCB) pada karyawan PT. Kronstrindo Putera Perkasa.

Berdasarkan masalah tersebut Peneliti bertujuan untuk mengetahui dan menganalisis pengaruh gaya kepemimpinan transformasional, gaya kepemimpinan transaksional dan kepuasan kerja serempak terhadap Organizational Citizenship Behavior (OCB) karyawan PT.Kronstrindo Putera Perkasa, Untuk mengetahui dan menganalisis pengaruh gaya kepemimpinan transformasional terhadap Organizational Citizenship Behavior (OCB) karyawan PT.Kronstrindo Putera Perkasa, Untuk mengetahui dan menganalisis pengaruh gaya kepemimpinan transaksional terhadap Organizational Citizenship Behavior (OCB)karyawan PT.Kronstrindo Putera Perkasa, Untuk mengetahui dan menganalisis 
pengaruh kepuasan kerja terhadap Organizational Citizenship Behavior (OCB)karyawan PT. Kronstrindo Putera Perkasa.

Tercapainya penelitian ini, diharapkan dapat memberikan manfaat bagi berbagai pihak, diantaranya: Bagi PT.Kronstrindo Putera Perkasa, penelitian ini diharapkan memberikan masukan yang baik bagi direktur dan karyawan PT.Kronstrindo Putera Perkasa agar mengetahui hubungan variabel antara gaya kepemimpinan transformasional, transaksional dan kepuasan kerja dengan Organizational Citizenship Behavior (OCB), Bagi penulis, penelitian ini memberikan tambahan wawasan dan pengetahuan bagi penulis khususnya dan bagi kalangan mahasiswa lain pada umumnya dalam bidang manajemen sumber daya manusia serta memberikan pembelajaran lebih mengenai gaya kepemimpinan transaksional, kepuasan kerja dan Organizational Citizenship Behavior (OCB), Bagi pihak lain, manfaat penelitian ini adalah sebagai bahan referensi dan bahan perbandingan bagi penulis lain dalam melakukan penelitian yang sejenis dimasa yang akan datang.

\section{KAJIAN LITERATUR DAN PENGEMBANGAN HIPOTESIS}

\section{Gaya Kepemimpinan Transformasional}

Nawawi dalam Palgunanto (2010:69), kepemimpinan transformasional adalah pendekatan kepemimpinan dengan melakukan usaha dengan mengubah kesadaran membangkitkan semangat dan mengilhami bawahan atau anggota organisasi untuk mengeluarkan usaha ekstra dalam mencapai tujuan organisai, tanpa merasa ditekan atau tertekan. Dimensi-dimensi dalam kepemimpinan transformasional, dengan penjelasannya Bass dalam Dewi (2010:5) adalah:

1. Individualized influence / Pengaruh Individu, yaitu melalui model-model aturan bagi pengikut, yang mana pengikut mengidentifikasi dan ingin melakukan melebihi model tersebut. Pemimpinpemimpin menunjukkan standard tinggi dari tingkah laku moral dan etika, serta menggunakan kemampuan untuk menggerakkan individu maupun kelompok terhadap pencapaian misi mereka dan bukan untuk nilai perorangan.

2. Inspirational motivation, yaitu pemimpin memberikan arti dan tantangan bagi pengikut dengan maksud menaikkan semangat dan harapan, menyebarkan visi, komitmen pada tujuan dan dukungan tim.

3. Intellectual stimulation, yaitu pemimpin transformasional menciptakan rangsangan dan berpikir inovatif bagi pengikut melalui asumsi-asumsi pertanyaan, merancang kembali masalah, menggunakan pendekatan pada situasi lampau melalui cara yang baru.

4. Individualized consideration, yaitu pendekatan Individu (melalui pemberian bantuan sebagai pemimpin, memberikan pelayanan sebagai mentor, memeriksa kebutuhanb individu untuk perkembangan dan peningkatan keberhasilan.

\section{Gaya Kepemimpinan Transaksional}

Gaya kepemimpinan transaksional yaitu membuat kontrak dengan pengikut terkait dengan konsekuensi-konsekuensi dalam mencapai berbagai harapan yang telah ditetapkan, seperti imbalan untuk penyelesaian tugas yang adil dan saling menguntungkan (Sashkin, 2011:73). Menurut Bass dalam Rusdiyanto (2015) gaya kepemimpinan transaksional adalah gaya kepemimpinan yang memperlakukan bawahan untuk mendapat hukuman atau hadiah dalam pelaksanaan tugasnya. Dalam bentuk gaya kepemimpinan transaksional ini, pemimpin berinteraksi dengan bawahannya berdasarkan proses transaksi (ganjaran formal). Gaya kepemimpinan transaksional, dimensi gaya kepemimpinan transaksional Bass dan Avolio dalam Munandar (2001) terdiri atas:

1. Contingent Reward, yaitu Jika bawahan melakukan pekerjaan untuk perusahaan dan menguntungkan perusahaan, maka mereka dijanjikan imbalan yang setimpal, mereka dapat mengharapkan untuk memperoleh imbalan yang setimpal, serta atasan mampu menghargai 
prestasi yang telah dicapai bawahan ketika tujuan-tujuan organisasi tercapai. Transaksinya ialah: "jika anda bekerja dengan baik, maka akan saya berikan imbalan yang baik".

2. Management By Exception-Active, yaitu manajer atau pemimpin secara aktif akan ketat memantau pelaksaan tugas pekerjaan bawahannya agar mereka tidak membuat kesalahankesalahan atau agar mereka tidak gagal dalam melaksanakan pekerjaan.

3. Management By Exception-Passive, yaitu manajer atau pimpinan baru bertindak setelah terjadinya kegagalan yang dilakukan oleh bawahannya, tindakan pemimpin tersebut dilakukan untuk mencapai tujuan organisasi atau setelah benar-benar timbul masalah yang serius.

4. Laissez Farie, yaitu manajer memberikan kepercayaan pada bawahannya agar dapat melakukan tugas pekerjaan tanpa ada pengawasan dari dirinya.

\section{Kepuasan Kerja}

Kepuasan kerja merupakan derajat atau tingkatan perasaan positif maupun negatif seorang individu terhadap pekerjaannya. Kepuasan kerja merupakan sikap atau respon emosional terhadap tugas seseorang sebagaimana kondisi fisik dan sosial ditempat kerja, Schermerhorn dalam Purnami (2013). Meningkatnya kepuasan kerja yang dirasakan pegawai mempengaruhi perilaku pegawai dalam kondisi kerja sehari-hari, perubahan perilaku tersebut menunjukkan ciri-ciri yang terdapat dalam komponen perilaku kewarganegaraan organisasi yang dikemukakan oleh Luthans dalam Arifiani (2016) Dimensi Kepuasan Kerja terdiri dari:

1. Pekerjaan itu sendiri, yaitu pekerjaan Mendapat tugas kerja yang menarik, Kesempatan untuk belajar.

2. Pengawasan, yaitu kemampuan penyelia untuk memberikan bantuan teknis dan dukungan perilaku.

3. Hubungan dengan rekan kerja, yaitu rekan kerja memberikan bantuan teknis dan dukungan sosial.

4. Kesempatan Promosi, yaitu kesempatan untuk maju dalam organisasi, guna meningkatkan kualitas karyawan.

5. Gaji, yaitu sejumlah upah yang diterima sesuai dengan kinerja.

\section{Organizational Citizenship Behavior}

Organizational Citizenship Behavior adalah perilaku individual yang bersifat bebas (discretionary), yang tidak secara langsung dan eksplisit mendapat penghargaan dari sistem imbalan formal, dan yang secara keseluruhan mendorong keefektifan fungsi-fungsi organisasi, Organizational Citizenship Behavior mempunyai lima dimensi Organ dalam Rusdiyanto (2015), yaitu:

1. Altruism, yaitu perilaku membantu meringankan pekerjaan yang ditujukan kepada rekan kerja dalam suatu organisasi dan memberi arahan kepada rekan kerja dalam memaksimalkan kinerjanya.

2. Conscientiousness, yaitu Melakukan hal-hal yang menguntungkan organisasi melampaui persyaratan minimal yang dibutuhkan. Contoh perilaku dari dimensi ini diantaranya adalah mematuhi peraturan-peraturan di organisasi meskipun tidak ada yang mengawasi, selalu tepat waktu dalam hal-hal yang berkaitan dengan pekerjaan, tidak membuang-buang waktu kerja, membersihkan dan merapikan tempat atau peralatan bekerja setelah digunakan, ikut memelihara sumber daya dan hal-hal yang berkaitan dengan pemeliharaan internal.

3. Sportsmanship, yaitu Toleransi pada situasi yang kurang ideal atau tidak nyaman yang terjadi ditempat kerja tanpa mengeluh. karyawan tidak menghabiskan waktu untuk mengeluhkan hal-hal yang berkaitan dengan pekerjaan maupun lingkungan kerjanya, tidak membesar besarkan masalah yang terjadi di organisasi, mampu mengambil sisi positif dari kondisi yang terjadi. 
4. Courtesy, yaitu Membantu mencegah timbulnya masalah dengan rekan kerja. Contoh perilaku dari dimensi ini diantaranya adalah mempertimbangkan dampak dari tindakan yang akan dilakukannya terhadap rekan kerjanya, memberi konsultasi dan informasi yang diperlukan kepada rekan kerja, menjaga hubungan baikdengan rekan kerja, serta menghargai hak dan privasi mereka.

5. Civic virtue, yaitu Terlibat dan ikut bertanggung jawab dalam kegiatan-kegiatan organisasi dan peduli pada kelangsungan hidup organisasi. Tidak hanya aktif dalam mengemukakan pendapat tetapi aktif menghadiri pertemuan-pertemuan dan terus mengikuti perkembangan isu-isu yang terjadi di organisasi. Mengambil inisiatif rekomendasi atau saran inovatif untuk meningkatkan kualitas organisasi.

\section{Kerangka Pemikiran}

Dasar perilaku dari $O C B$ adalah dimana karyawan merefleksikan diri dengan suka menolong, perhatian dan sungguh-sungguh. Sikap ini yang akan nampak dari karyawan yang terlibat $O C B$. Organ dalam Rusdiyanto (2015) menyatakan ada lima dimensi dari perilaku OCB ini Altruism (suka menolong secara suka rela dalam hal pekerjaan), Civic virtue (meningkatkan performa dan kemajuan organisasi), Conscientiousness (mengikuti peraturan, ketetapan waktu), Courtesy (Perilaku proaktif yang bertujuan untuk menghindari potensi masalah yang akan timbul dalam organisasi) dan Sportmanship (menjaga informasi dan tidak membesarkan masalah).

Perilaku seorang pemimpin dalam mengelola dan memimpin organisasi atau perusahaan dapat pula mempengaruhi munculnya perilaku $O C B$ pada karyawan. Dua varian gaya kepemimpinan yang diformulasikan oleh Bass didalam beberapa bukunya, yaitu gaya kepemimpinan transaksional dan transformasional diasumsikan memiliki dampak signifikan terhadap perilaku $O C B$.

Gaya kepemimpian transformasional yakni pemimpin yang mencurahkan perhatiannya kepada persoalan yang di hadapi karyawannya serta kebutuhan pengembangan diri karyawannya dengan memberi semangat hingga karyawannya ikut terlibat dalam ekstra peran seperti $O C B$. Dimensi gaya kepemimpinan transformasional yaitu : Pengaruh Individu, Inspirational Motivation, Intellectual Stimulation, dan Pendekatan Individu Sedangkan gaya kepemimpinan Transaksional berupaya memotivasi bawahan dengan memberikan imbalan sebagai pertukaran atas usaha yang telah dilakukan oleh bawahan bagi kemajuan organisasi atau perusahaan. Empat aspek yang dari gaya kepemimpinan transaksional Bass dan Avolio dalam Munandar (2001) yaitu: Contigent reward, Management by exception-aktive, Management by exception-passive, dan Laissez faire.

Selain Gaya Kepemimpinan yang menjadi faktor timbulnya pengaruh $O C B$ Pada Karyawan adalah Kepuasan kerja, Kepuasan kerja merupakan suatu penentu utama dari $O C B$. Pekerja yang puas pasti akan berbicara positif mengenai organisasi, membantu karyawan yang lain, dan melebihi ekspektasi normal dalam pekerjaannya Robbins dalam Arifiani (2016). Kepuasan kerja memiliki dimensi yaitu: Pekerjaan itu sendiri, Gaji, Kesempatan Promosi, Pengawasan, dan Rekan Kerja Luthans dalam Arifiani( 2016). Berdasarkan uraian kerangka pemikiran diatas, dapat dilihat kerangka pemikiran yang diajukan dalam penelitian ini pada gambar 1 sebagai berikut: 


\section{Kerangka Pemikiran}

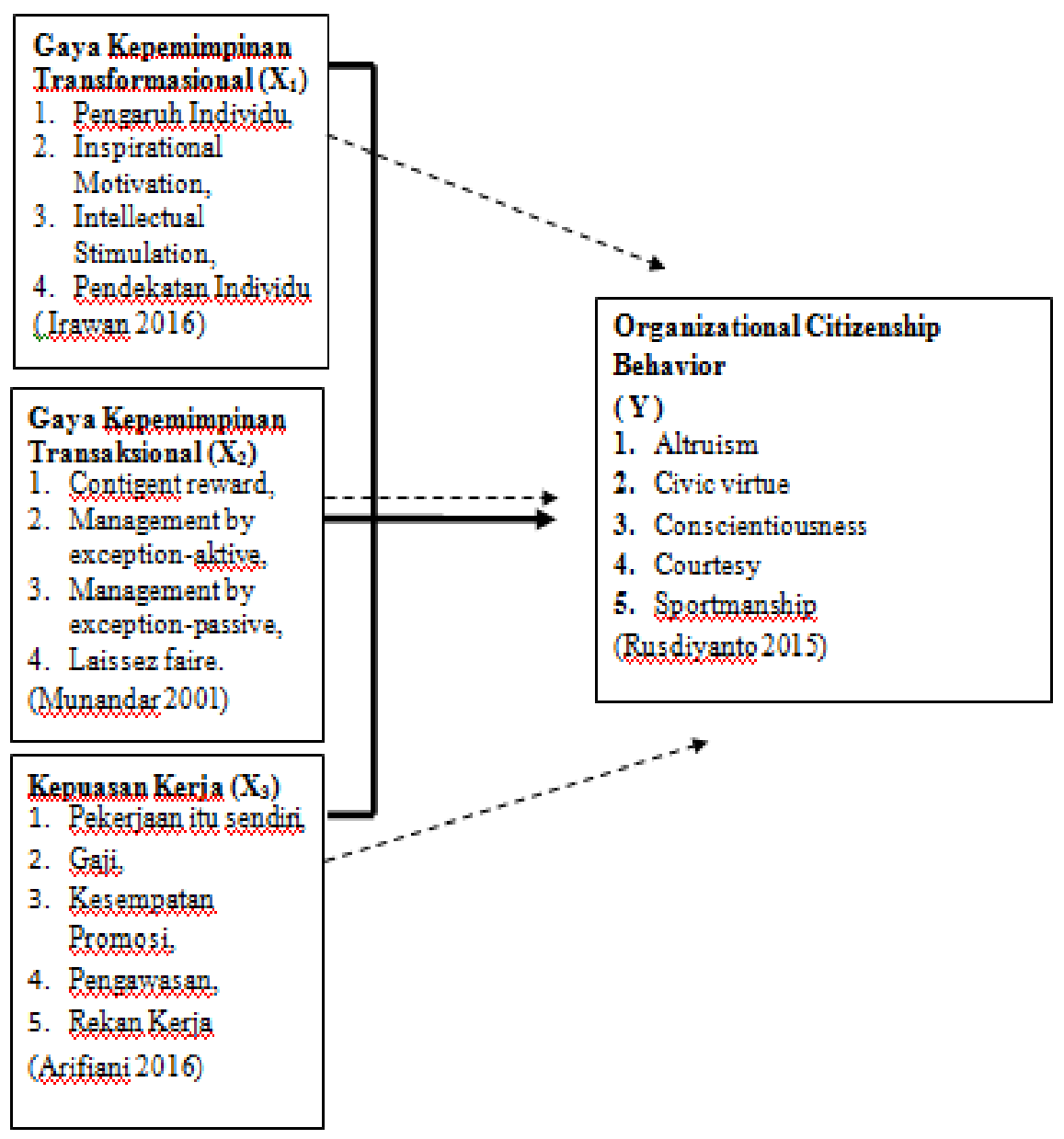

\section{Gambar 1 \\ Kerangka Pemikiran}

\section{Hipotesis}

Hipotesis merupakan jawaban sementara atas suatu permasalahan yang masih harus dibuktikan kebenarannya secara empiris. Sesuai dengan permasalahan untuk saat ini pada penelitian yang akan diteliti, maka dirumuskan hipotesis penelitian sebagai berikut:

1. Diduga gaya kepemimpinan transformasional, gaya kepemimpinans transaksional dan kepuasan kerja berpengaruh simultan/serempak terhadap Organizational Citizenship Behavior (OCB).

2. Diduga gaya kepemimpinan transformasional berpengaruh parsial terhadap Organizational Citizenship Behavior (OCB).

3. Diduga gaya kepemimpinan transaksional berpengaruh parsial terhadap Organizational Citizenship Behavior (OCB).

4. Diduga kepuasan kerja berpengaruh parsial terhadap Organizational Citizenship Behavior (OCB).

\section{METODE PENELITIAN}

Jenis Penelitian ini adalah penelitian deskripsi, Penelitian Deskriptif adalah penelitian yang dilakukan untuk mengetahui nilai variabel mandiri, baik satu variabel atau lebih (independen) tanpa membuat perbandingan, atau menghubungkan dengan variabel lain. Lokasi perusahaan penelitian ini di PT.Kronstrindo Putera Perkasa Palu, Jl. Soekarno Hatta Ruko Perum Pesona Nokilalaki No.5 Palu. Penelitian kuantitatif yaitu Metode yang data penelitianya berupa Angka-angka dan analisis 
menggunakan statistik dengan kaidah ilmiah yaitu kongkrit, obyektif, terukur, rasional dan sistematis (Sugiyono, 2014:7).

Populasi dalam penelitian ini adalah seluruh karyawan PT.Kronstrindo Putera Perkasa mulai dari kepala bidang, staff dan tenaga kerja tidak tetap sebanyak 35 Orang tahun 2016-2017 dan yang dinilai sebagai pimpinan adalah direktur utama PT.Kronstrindo Putera Perkasa. Menurut Sugiyono (2014:215) Populasi adalah wilayah generalisasi yang terdiri atas obyek/subyek yang mempunyai kualitas dan karakteristik tertentu yang ditetapkan oleh peneliti untuk dipelajari dan kemudian ditarik kesimpulannya.

Sugiyono (2014:85) Teknik sampling dalam penelitian ini menggunakann sampling jenuh yakni "teknik pengambilan sampel apabila semua populasi digunakan sebagai sampel dengan jumlah 35 sampel dan dikenal juga dengan istilah sensus". Metode pengumpulan data yang dibutuhkan, peneliti menggunakan metode menurut Sugiyono (2014:224) yakni wawancara, menyebar kuesioner, dan observasi dengan skala pengukuran menggunakan skala likert, untuk mengukur sikap, pandapat, dan persepsi seseorang atau sekelompok orang tentang fenomena sosial (Sugiyono 2014:93). Melalui skala likert, maka variabel yang akan diukur dijabarkan menjadi indikator variabel. Hingga dijadikan sebagai titik tolak untuk menyusun item-item instrumen yang dapat berupa pernyataan atau pertanyaan.

Mengukur valid atau tidaknya data yang diteliti, digunakan uji validitas dan uji reliabilitas, Validitas atau valid merupakan instrumen yang dapat digunakan untuk mengukur apa yang seharusnya diukur (Sugiyono 2014:121) sedangkan uji reliabilitas adalah suatu angka indeks yang menunjukkan konsistensi suatu alat pengukur di dalam mengukur gejala yang sama. Suatu kuesioner dikatakan reliabel atau handal jika jawaban seseorang terhadap pernyataan adalah konsisten atau stabil dari waktu ke waktu. Model umum bentuk persamaan alat analisis statistik parametrik Regresi Linear Berganda (Multiple Linear Regression). Menurut Sanusi (2014:135), dapat digambarkan dengan rumus:

$\mathrm{Y}=\mathrm{a}+\mathrm{b}_{1} \mathrm{X}_{1}+\mathrm{b}_{2} \mathrm{X}_{2}+\mathrm{b}_{3} \mathrm{X}_{3}$

dengan keterangan:

$\mathrm{Y}=$ Organizational Citizenship Behavior

$\mathrm{X}_{1}=$ Gaya Kepemimpinan Transformasional

$\mathrm{X}_{2}=$ Gaya Kepemimpinan Transaksional

$\mathrm{X}_{3}=$ Kepuasan Kerja

a $=$ Konstanta

$\mathrm{b}_{1}, \mathrm{~b}_{2}, \mathrm{~b}_{3}=$ Koefisien regresi

\section{HASIL DAN PEMBAHASAN}

\section{Deskripsi Karakteristik Responden}

Jumlah responden Laki-laki lebih banyak dibandingkan responden Perempuan dengan hasil Lakilaki $=69 \%$ dan Perempuan $=31 \%$, karyawan yang berusia 31-40 tahun lebih banyak dibandingkan karyawan yang berusia diatas maupun dibawah 31-40 tahun, karyawan yang memiliki pedidikan Sarjana lebih banyak daripada yang lainnya dengan hasil sarjana $=91 \%$. 
Indra, B.A.

\section{Uji Multikolonieritas}

Tabel 2. Hasil Pengujian Multikolinearitas

\begin{tabular}{|c|c|c|c|}
\hline \multirow{2}{*}{ Variabel Independen } & \multicolumn{2}{|c|}{ Collinierity Statistic } & \multirow{2}{*}{ Keterangan } \\
\cline { 2 - 3 } & Tolerance & VIF & Non Multikolinieritas \\
\hline $\begin{array}{c}\text { Gaya Kepemimpinan } \\
\text { Transformasional }\end{array}$ & 0,470 & 2,126 & Non Multikolinieritas \\
\hline $\begin{array}{c}\text { Gaya Kepemimpinan } \\
\text { Transaksional }\end{array}$ & 0,435 & 2,296 & Non Multikolinieritas \\
\hline Kepuasan Kerja & 0,882 & 1,134 & \\
\hline
\end{tabular}

Berdasarkan hasil uji multikolonieritas yang di lakukan, dapat diketahui bahwa nilai Tolerance value variabel gaya kepemimpinan transformasional, gaya kepemimpinan transaksional dan kepuasan kerja yang diperoleh $<0,10$ dan nilai VIF $<10$. Maka dapat disimpulkan bahwa dalam penelitian ini tidak terjadi multikolinearitas dan penelitian ini dapat dilanjutkan.

\section{Uji Normalitas}

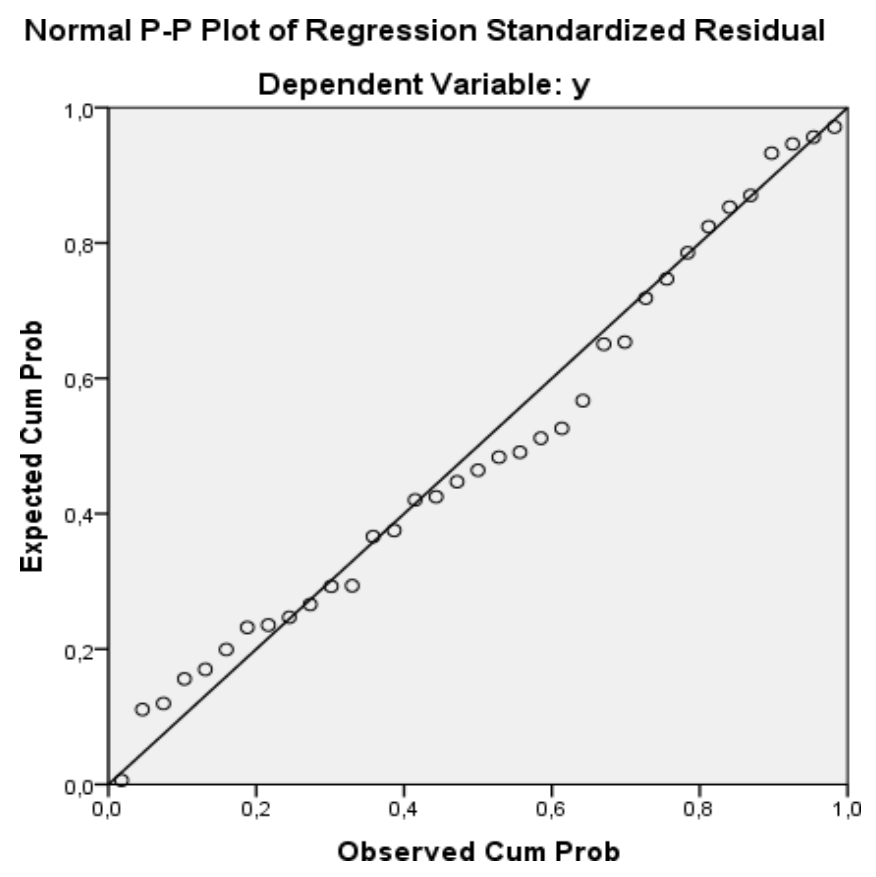

Gambar 2 Hasil Uji Normalitas

Gambar di atas dapat dilihat bahwa pengujian data dengan menggunakan bantuan program statistik SPSS For Windows Release 15.0, diperoleh data hasil penelitian cenderung tersebar mendekati atau sekitar garis diagonal dan mengikuti arah garis diagonal sehingga asumsi normalitas dapat dikatakan terpenuhi. 


\section{Uji Heteroskedastisitas}

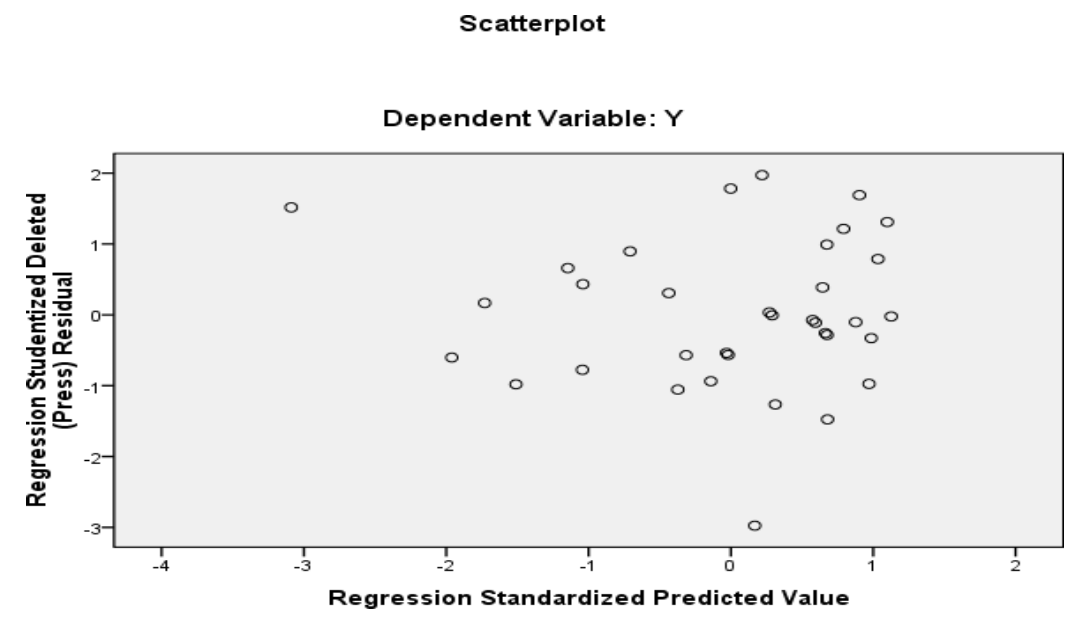

\section{Gambar 3. Hasil Uji Heteroskedastisi}

Terlihat titik-titik menyebar secara acak tidak membentuk sebuah pola tertentu dengan jelas, serta tersebar baik di atas maupun di bawah angka 0 pada sumbu Y, dengan menggunakan bantuan komputer program SPSS for windows versi 16.0, maka hal ini terjadi homoskedastisitas berarti tidak terjadi heteroskedastisitas pada model regresi, sehingga model tersebut layak digunakan.

\section{Uji F (Simultan)}

Gaya Kepemimpinan Transformasional, Gaya Kepemimpinan Transaksional dan Kepuasan Kerja Secara Simultan berpengaruh terhadap Organizational Citizenship Behavior (OCB). Berdasarkan penelitian yang telah dilakukan dengan hasil nilai $F=0,000<0,05$. Hal ini menggambarkan bahwa PT.Konstrindo Putera Perkasa sudah menerapkan gaya kepemimpinan transformasional, gaya kepemimpinan transaksional dan kepuasan kerja berpengaruh pada Organizational Citizenship Behavior (OCB) Karyawan Konstrindo Putera Perkasa.

\section{Uji T (Parsial)}

1. Berdasarkan penelitian yang telah dilakukan tingkat signifikansi t sig yang diperoleh sebesar $0,000<\alpha 0,05$. Dapat diartikan bahwa semakin besar gaya kepemimpinan transformasional maka akan sangat mempengaruhi OCB PT.Konstrindo Putera Perkasa.

2. Berdasarkan hasil penelitian yang telah dilakukan tingkat signifikansi t sig yang diperoleh sebesar $0,019<\alpha 0,05$. Dapat diartikan bahwa semakin tinggi gaya kepemimpinan transaksional maka akan sangat mempengaruhi OCB perusahaan ini dan bernilai positif.

3. Berdasarkan hasil penelitian yang telah dilakukan hasil uji t tingkat signifikansi $t$ sig yang diperoleh sebesar $0,017<\alpha 0,05$. Dapat diartikan bahwa semakin tinggi tingkat kepuasan kerja maka akan sangat mempengaruhi OCB perusahaan ini dan bernilai positif

\section{Hasil Analisis Regresi Linear Berganda}

Menguji kebenaran hipotesis yang diajukan dalam penelitian ini, menggunakan metode analisis regresi linear berganda, sementara itu untuk menguji permasalahan dan hipotesis pertama yang telah dirumuskan digunakan uji $\mathrm{F}$, sedangkan untuk menguji permasalahan dan hipotesis kedua digunakan uji t, dengan menggunakan program SPSS For Windows Release 15.0. Adapun hasil analisis tersebut: $\mathrm{Y}=0.142+0,610 \mathrm{X} 1+0,198 \mathrm{X} 2+0,190 \mathrm{X} 3$. 


\section{Uji Dominan}

Uji dominan digunakan untuk mengetahui variabel independa mana yang paling berpengaruh dominan terhadap variabel dependen, Pengujian melalui uji dominan dapat dilihat dari standardized coefficients Beta yang paling besar nilainya, yang diketahui gaya kepemimpinan transformasional (X1) nilai betanya $0.708 / 70,8 \%$, gaya kepemimpinan transaksional(X2) nilai betanya $0.286 / 28,6 \%$ dan kepuasan kerja $0.204 / 20,4 \%$ sehingga dapat diketahiu bahwa variabel yang berpengaruh paling dominan adalah Gaya Kepemimpinan Transformasional yang memiliki nilai Beta tertinggi yaitu 0.708 atau $70,8 \%$. Hal ini menunjukkan bahwa hipotesis yang menyatakan "Gaya Kepemimpinan Transformasional berepengaruh paling dominan terhadap Organizational Citizenship Behavior PT.Konstrindo Putera Perkasa.

\section{KESIMPULAN DAN SARAN}

\section{Kesimpulan}

Berdasarkan dari hasil analisis dan pembahasan yang dilakukan, maka dapat disimpulkan variabel gaya kepemimpinan transformasional $\left(\mathrm{X}_{1}\right)$ gaya kepemimpinan transaksional $\left(\mathrm{X}_{2}\right)$ dan kepuasan kerja $\left(\mathrm{X}_{3}\right)$ secara bersama-sama berpengaruh terhadap organizational citizenship behavior (OCB) karyawan pada PT.konstrindo putera perkasa begitu juga variabel gaya kepemimpinan transformasional $\left(\mathrm{X}_{1}\right.$, variabel gaya kepemimpinan transaksional $\left(\mathrm{X}_{2}\right)$ dan variabel kepuasan kerja $\left(\mathrm{X}_{3}\right)$ secara parsial berpengaruh terhadap organizational citizenship behavior (OCB) karyawan pada PT.konstrindo putera perkasa.

\section{Saran}

Berdasarkan kesimpulan dari penelitian, ada beberapa upaya perlu dilakukan untuk lebih menghidupkan lagi suasana dalam berorganisasi di PT.Konstrindo Putera Perkasa, melalui peningkatan perilaku OCB pada karyawan itu sendiri, diantaranya adalah sebagai berikut:

1. Pada variabel Gaya Kepemimpinan Transformasional, diketahui pimpinan kurang membagikan ilmu pengetahuan serta pengalamannya kepada karyawan baru, kurang memberikan nasehat serta solusi bila karyawan ada permasalahan, kurang memberi pembinaan, sehingga disarankan kepada pimpinan PT.Konstrindo Putera Perkasa, agar lebih meningkatkan lagi pembinaan keilmuan terhadap karyawan baru seperti memberikan seminar atau membagikan pengalaman kerjanya pada karyawan untuk bekerja lebih baik serta membina karyawan untuk meningkatkan etika karyawan.

2. Pada variabel Gaya Kepemimpinan Transaksional, diketahui pimpinan kurang memberikan penjelasan kerja terhadap karyawan bila terjadi kesalahan kerja, Pimpinan kurang memberi intervensi terutama ketika karyawan membuat kesalahan, Pimpinan kurang percaya pada keahlian karyawan serta pimpinan tidak berani memberikan tanggung jawab kerja sepenuhnya terhadap karyawan sehingga disarankan kepada pimpinan PT.Konstrindo Putera Perkasa, agar lebih memberdayakan karyawannya untuk lebih ahli dan terampil pada jabatan yang telah di berikan, Pimpinan disarankan lebih memantau lagi kinerja karyawan saat bekerja agar tidak ada lagi kesalahan kerja yang dilakukan karyawan serta lebih menegaskan lagi segala upaya dan kinerja yang harus ditingkatkan karyawan guna mencapai tujuan organisasi PT.Konstrindo Putera Perkasa selaku tanggung jawab karyawan perusahaan PT.Konstrindo Putera Perkasa.

3. Pada variabel Kepuasan Kerja, diketahui Karyawan merasa kemampuannya belum sesuai dengan pekerjaan yang diterima, pimpinan kurang memberikan balas jasa atas kinerja karyawan, gaji yang diberikan karyawan belum cukup untuk memenuhi kebutuhan karyawan, pengawasan dan keterbukaan pimpinan untuk menampung pendapat dan saran karyawan sangat kurang, kerja tim antar karyawan masih belum maksimal serta fasilitas kerja yang diberikan karyawan juga belum 
maksimal, sehingga disarankan kepada pimpinan PT.Konstrindo Putera Perkasa, untuk mendorong karyawan agar lebih percaya diri dalam mengerjakan kerja-kerja perusahaan, pimpinan disarankan untuk lebih memperhatikan balas jasa yang dilakukan karyawan pada perusahaan, Pimpinan disarankan untuk lebih menghargai prestasi kerja karyawan agar karyawan terpacu dalam membawa perusahaan menjadi lebih baik lagi, pimpinan disarankan bisa menaikan gaji karyawan sesuai dengan kebutuhan hidup karyawan dimasa saat ini, pimpinan disarankan lebih terbuka pada karyawan dan mau menampung pendapat dan saran yang baik oleh karyawan untuk meningkatkan performa perusahaan serta pimpinan disarankan meningkatkan lagi fasilitas kerja karyawan agar kinerja karyawan lebih maksimal lagi seperti kebutuhan teknologi dan kenyamanan dalam ruang kerja.

4. Pada variabel Organizational Citizenship Behavior (OCB), diketahui karyawan kurang saling membantu dalam mengerjakan tugas perusahaan, masih banyak karyawan yang acuh tak acuh untuk menjaga nama baik perusahaan, antara karyawan kurang menjaga moral dalam berperilaku dan karyawan banyak yang merasa belum memberikan kinerja terbaiknya sehingga disarankan kepada pimpinan PT.Konstrindo Putera Perkasa, memberikan arahan pada karyawan untuk lebih meningkatkan rasa saling membantu dalam mencapai tujuan perusahaan dengan memberi nasehat pada karyawan, pimpinan memberikan kesadaran akan pentingnya menjaga nama baik perusahaan untuk keberlangsungan perusahaan, pimpinan mengarahkan bawahan untuk saling menjaga etika baik dalam internal organisasi perusahaan ataupun eksternal organisasi perusahaan serta pimpinan disarankan memberikan dorongan berupa penghargaan atau reward yang lebih kepada karyawan agar karyawan yakin untuk memberikan kinerja terbaiknya.

5. Diharapkan kepada peneliti selanjutnya agar menggunakan variabel lain yang dapat mempengaruhi Organizational Citizenship Behavior (OCB) sehingga dapat memberikan manfaat maupun pembelajaran kepada pihak yang berkepentingan.

\section{REFERENSI}

Arifiani, R.S., Endang,S.A., \& Ika, Ruhana. (2016). Pengaruh Kepemimpinan Transformasional Terhadap Organizational Citizenship Behavior dan Kepuasan Kerja Studi Pada Tenaga Perawat RSUD. Dr. Saiful Anwar Malang. Jurnal Administrasi, Bisnis Vol.33, No.1. Retrieved from http://administrasibisnis.studentjournal.ub.ac.id/index.php/jab/article/view/1284

Dewi, I.C. \& Nuri, Herachwati. (2010). analisis dampak kepemimpinan transaksional dan transformasional terhadap pembelajaran organisasi pada pt bangun satya wacana surabaya. Jurnal Manajemen Teori dan Terapan Tahun 3, No. 3, Doi: 10.20473/jmtt.v3i3.2405

Munandar, A.S. (2001). Psikologi industri dan organisasi. Depok: UI-Press.

Palgunanto,Yusuf,.suparno \& achmad dwityanto. (2010). kinerja karyawan ditinjau dari gaya kepemimpinan transformasional. indigenous, jurnal ilmiah berkala psikologi, vol. 12, no. 1, hal.66-73. Doi: 10.23917/indigenous.v12i1.1608.

Purnami, S.R. (2013).Pengaruh Kepuasan Kerja dan Komitmen Organisasi Terhadap Perilaku Kewargaan Organisasional terhadap Implikasinya Terhadap Kinerja Pegawai Administrasi Politeknik Komputer Niaga LPKIA. Jurnal Ilmu Manajemen dan Bisnis,Vol.04,No.01,Retrieved from http: http://ejournal.upi.edu/index.php/mdb/article/view/1002/656.

Rusdiyanto,W., \& Riani,A.L. (2015). pengaruh kepemimpinan transformasional dan transaksional terhadap kepuasan kerja dan organizational citizenship behavior. Jurnal Economia, Volume 11, No. 2,2015. Retrieved from http://dx.doi.org/10.21831/economia.v11i2.7950

Sanusi Anwar. (2014). Metodologi Penelitian Bisnis. Jakarta: Salemba Empat.

Sashkin, M., \& Sashkin,M.G. (2011). Prinsip-prinsip Kepemimpinan. Jakarta: Erlangga.

Sugiyono. (2014). Metode Penelitian Kuantitatif, Kualitatif, Dan R\&D. Bandung: Alfabeta. 
Indra, B.A.

Supit, I.Y.I. (2016). Pengaruh Gaya Kepemimpinan Transformasional Terhadap Komitmen Organisasional dan Organization Citizenship Behavior Yang Dimediasi Oleh Kepuasan Kerja Karyawan Non Medis RS.Pancaran Kasih Manado.Jurnal Riset Bisnis dan Manajemen,Vol.4,No3,hal.351-368.Retrieved from https: I/media.neliti.com/media/publications/127999-ID-pengaruh-gaya-kepemimpinantransformasio.pdf 